\title{
Areas of high conservation value in Georgia: present and future threats by invasive alien plants
}

\author{
Daniela Julia Klara Thalmann • David Kikodze • \\ Manana Khutsishvili • David Kharazishvili • Antoine Guisan · \\ Olivier Broennimann • Heinz Müller-Schärer
}

\begin{abstract}
Georgia is known for its extraordinary rich biodiversity of plants, which may now be threatened due to the spread of invasive alien plants (IAP). We aimed to identify (1) the most prominent IAP out of 9 selected potentially invasive and harmful IAP by predicting their distribution under current and future climate conditions in Georgia as well as in its 43 Protected Areas, as a proxy for areas of high conservation value and (2) the Protected Areas most at risk due to these IAP. We used species distribution models based on 6 climate variables
\end{abstract}

Olivier Broennimann and Heinz Müller-Schärer are joint senior authors.

\section{J. K. Thalmann $(\bowtie) \cdot H$. Müller-Schärer}

Department of Biology, Ecology and Evolution,

University of Fribourg, Chemin du Musée 10,

1700 Fribourg, Switzerland

e-mail: daniela.thalmann@bluewin.ch

H. Müller-Schärer

e-mail: heinz.mueller@unifr.ch

D. Kikodze · M. Khutsishvili

Institute of Botany, Ilia State University, Tbilisi, Georgia

D. Kharazishvili

Batumi Botanical Garden, Batumi, Georgia

A. Guisan · O. Broennimann

University of Lausanne, Lausanne, Switzerland and then filtered the obtained distributions based on maps of soil and vegetation types, and on recorded occurrences, resulting into the predicted ecological distribution of the 9 IAP'sat a resolution of $1 \mathrm{~km}^{2}$. Our habitat suitability analysis showed that Ambrosia artemisiifolia, (24 and $40 \%$ ) Robinia pseudoacaia (14 and $19 \%$ ) and Ailanthus altissima (9 and $11 \%$ ) have the largest potential distribution (predicted $\%$ area covered), with A. altissima the potentially most increasing one over the next 50 years (from 9 to $13 \%$ and from 11 to $25 \%$ ), for Georgia and the Protected Areas, respectively. Furthermore, our results indicate two areas in Georgia that are under specifically high threat, i.e. the area around Tbilisi and an area in the western part of Georgia (Adjara), both at lower altitudes. Our procedure to identify areas of high conservation value most at risk by IAP has been applied for the first time. It will help national authorities in prioritizing their measures to protect Georgia's outstanding biodiversity from the negative impact of IAP.

Keywords Biological invasion · Biodiversity · Protected Areas - Species distribution models SDM · Climate change $\cdot$ Conservation

\section{Introduction}

A significant component of human-caused global change is invasive species, which can act as active 
drivers of ecosystem changes (Gurevitch et al. 2011; Vilà et al. 2011). Furthermore, their impact is expected to increase under climate change (Pauchard et al. 2009). To protect global biodiversity from the effect of invasive alien plant species (IAP), it is important to identify regions most at risk of invasion, as well as local species that might be vulnerable to such invasions. As rare species are already especially threatened by human activities and environmental change, there is a special need to protect them from additional danger coming from alien invaders (Vicente et al. 2011). Besides, many invasive species cause various diseases (e.g., allergic rhinitis and severe asthma caused by Ambrosia artemisiifolia) in the population of affected areas. These health problems cause losses of work time and costs of medical visits and medication, and may prevent tourist from visiting these areas (Richter et al. 2013). Furthermore, projected climatic change will exacerbate the current situation and lead to more widespread health problems in the near future (Richter et al. 2013). In agriculture, many IAP are also significant agricultural weeds, causing yield loss in many crops (Müller-Schärer and Collins 2012).

In this study we focus on Georgia because it is known for its extraordinary rich biodiversity of plants and its unparalleled diversity of landscapes. Georgia is found within the Caucasus Region, which is ranked by Conservation International (Anonymous Conservation International 2012) among the planet's 34 most diverse and endangered hotspots (Mittermeier et al. 2005, 2012). It is also one of WWF's global 200 vulnerable eco-regions, identified as globally outstanding for biodiversity (Anonymous WWF 2012). Georgia has a unique flora and is a refuge for many plant species that are remnants of ancient Mediterranean flora. Of the approximately 4,400 species of vascular plants occurring in Georgia's $76,400 \mathrm{~km}^{2}$, about 380 species $(9 \%)$ are endemic. Increasing evidence indicates that this extraordinary wealth is now under threat due to the spread of alien plants, which has mainly increased due to changes in land use, cross-country pipeline construction and habitat destruction (Kikodze et al. 2010). Some of the alien plants have a high potential to become so called "transformer species", i.e. invasive species with a high impact on the ecosystem (Ehrenfeld 2010), and the impact of these invasive plants is increasing worldwide, with on average a decreased abundance and diversity of the resident species in invaded sites
(Pyšek et al. 2012). A recent survey in Georgia identified 380 alien plant species (excluding cultivated species), of which 134 species have become naturalized. Among these, 16 species have established in nature and spread to the detriment of native species and are thus considered as invasive following the definition by Richardson et al. (2000) and thus listed accordingly in Kikodze et al. (2010). For Georgia, it is thus important to (1) identify introductions of exotic species at an early stage, (2) monitor their potential to become invasive, and (3) predict areas where they could spread. The two first steps have recently been performed in Georgia by Kikodze et al. (2010). What remains to be done is to determine where these species could spread.

The question of how plant species are distributed on Earth has a long history in ecology. Today, this question is tackled with modelling approaches that have their roots in quantifying species-environmental relationships (Guisan and Thuiller 2005). Predictive species distribution modelling can provide a useful and cost effective tool for conservation planning and biodiversity management (Araújo and Guisan 2006; Rodriguez et al. 2007; Guisan et al. 2013). Species distribution modelling is an ideal method to determine how invasive plant species are distributed and how further they may spread (e.g. Thuiller et al. 2005; Petitpierre et al. 2012). One way to assess the pressure of invasive species on the native flora is to define the geographical overlap between areas predicted suitable for an invasive species and the distribution of native rare and endangered species (Vicente et al. 2011). It is also important to determine how this impact on the native flora is likely to change in the future with changing climate (Dirnbock et al. 2003). Therefore, the distributions of such native and exotic plant invaders need to be determined both under current and future climatic conditions.

Instead of directly assessing the distribution of rare endangered plant species, already established "Protected Areas" can be used as a proxy. In the definition of the IUCN, Protected Areas are "a clearly defined geographical space, recognised, dedicated and managed, through legal or other effective means, to achieve the long-term conservation of nature with associated ecosystem services and cultural values" (Dudley 2008). Therefore, these Protected Areas are a good way to delimit areas of high conservation value with regard to plant biodiversity, including a larger 
number of such endangered plant species that need specific protection. Moreover they are also reasonable units to manage and provide other services to the public, e.g. for eco-tourism, which is an important source of income for the economy of Georgia (Kikodze and Gokhelashvili 2007).

For efficient cost-and-time-effective conservation, it is important to prioritize and identify those areas, which are under the biggest risks, and those plant invaders with the highest risk to infer negative impact, with the predicted range size as a first dimension determining impact (Parker et al. 1999). In this paper we identify the areas with the highest conflict rate between biological invasion and conservation value by measuring the overlap between the areas of potential invasions by the most problematic alien species and the Protected Areas in Georgia. We applied the following three-step procedure: (1) we mapped the 43 Protected Areas of Georgia, (2) predicted the potential suitable areas of nine selected IAP in Georgia under current and future climate conditions and (3) overlaid the maps of the predicted IAP occurrences with the Protected Areas of Georgia to identify the most prominent IAP and to determine areas most at risk of invasions.

\section{Methods \\ Study area}

The study area is Georgia, located at the crossroads of Western Asia and Eastern Europe, between latitudes $41^{\circ}$ and $44^{\circ} \mathrm{N}$, and longitudes $40^{\circ}$ and $47^{\circ}$ E, with an area of $67,900 \mathrm{~km}^{2}$ (Fig. 1). It is bounded by the Black Sea to the west, Russia to the north, Turkey and Armenia to the south, and Azerbaijan to the southeast. The climate of Georgia is extremely diverse, considering the nation's small size. There are two main climatic zones, roughly separating the eastern and western parts of the country. The Greater Caucasus Mountain Range plays an important role in moderating Georgia's climate, protecting it from colder air masses from the north. The Lesser Caucasus Mountains partially protect the region from the influence of dry and hot air masses from the south. Climatic zones are determined by distance from the Black Sea (west to east) and by altitude (greater to lesser Caucasus) and ranges from subtropical to continental zones.
Invasive study species

In Georgia, 16 invasive species have been identified by Kikodze et al. (2010) based on the definition by Richardson et al. (2000). Out of these 16 species, the nine presently most abundant or with a high potential to rapidly spread and cause impact on sensitive ecosystems (Table 1). This selection process was based on the author's expert knowledge on their status in other countries and available scoring systems for prioritizing IAP combined with local knowledge on habitat vulnerability and occurrences of endangered endemic plants, but no specific scoring system has been applied (cf. e.g. Leung et al. 2012, for a review on scoring systems).

Among these species, four originate from North America: one tree (Robinia pseudoacacia, a forest pant), two shrubs (Opuntia humifusa and Opuntia phaeacantha both dry grassland plants) and one herb (A. artemisiifolia classified as ruderal plant). The other five originate from East Asia: three shrubs (Vitex rotundifolia a pioneer plant, Clerodendrum bungei and Spiraea japonica, both ruderal plants), one herb (Miscanthus sinensinsis, a ruderal plant), and one tree (Ailanthus altissima, a dry grassland plant). These invasive plants have been naturalized and produce reproductive offspring, often in very large numbers, at large distances from parental plants and thus have a high potential to spread (Kikodze et al. 2010).

Collection of species occurrence data

To run the species distribution models, geographic coordinates representing the species occurrence are needed. In a classical approach, data from the native range of a species are used to train the models and then to project them into potential invaded ranges. Following Broennimann and Guisan (2008) we used pooled data from all the ranges of a species to fit the models. This approach accounts for eventual niche shifts during invasions of the new range (Broennimann et al. 2007). Even though niche shifts are in general rare among terrestrial plant invaders (Petitpierre et al. 2012), we chose to include all available data to obtain more accurate models for an improved prediction of the distribution in the invaded range (see also Beaumont et al. 2009). Therefore, occurrence data were selected for the native and invasive species range on a 

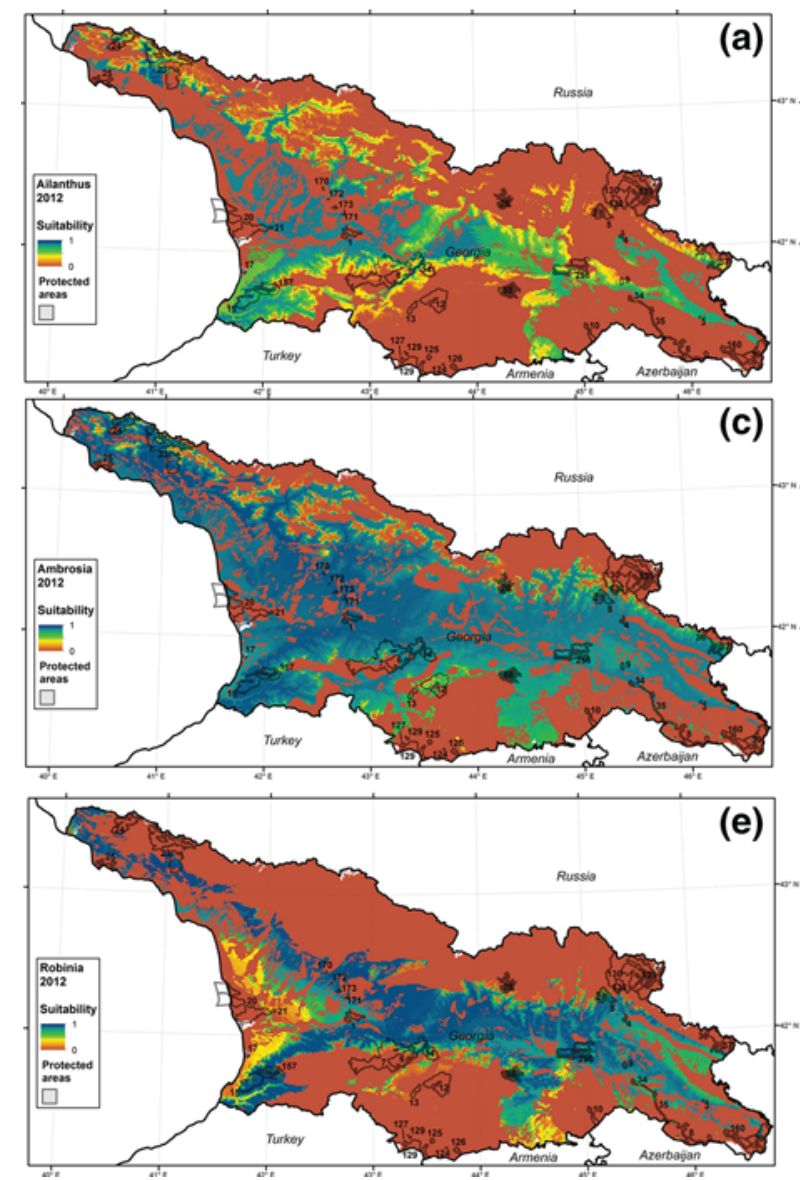

Fig. 1 Predicted potential distribution in Georgia based on native and invasive climatic niches and after considering the environmental filters at present climatic conditions $(\mathbf{a}, \mathbf{c}, \mathbf{e})$ and in $2060(\mathbf{b}, \mathbf{d}, \mathbf{f})$ for of A. artemisiifolia $(\mathbf{a}, \mathbf{b})$, R. pseudoacacia

global scale. At global scale, different online herbarium and state agencies were screened to obtain a dataset as complete as possible. A list of the databases used is given in Annex 1. Only data with a precision higher than $1 \mathrm{~km}$ were used. For additional occurrence data in Georgia, herbarium records were also taken from the Tbilisi State University Herbarium and the Batumi Botanical Garden Herbarium. These occurrence data were completed by several field surveys conducted by the authors across Georgia in 2011 and 2012 (cf. Annex 2). The coordinates of the occurrences were recorded with a Garmin eTrex ${ }^{\circledR} 12$ parallel channel GPS receiver. A table with the number of records by species and sampling method is given in Annex 2.
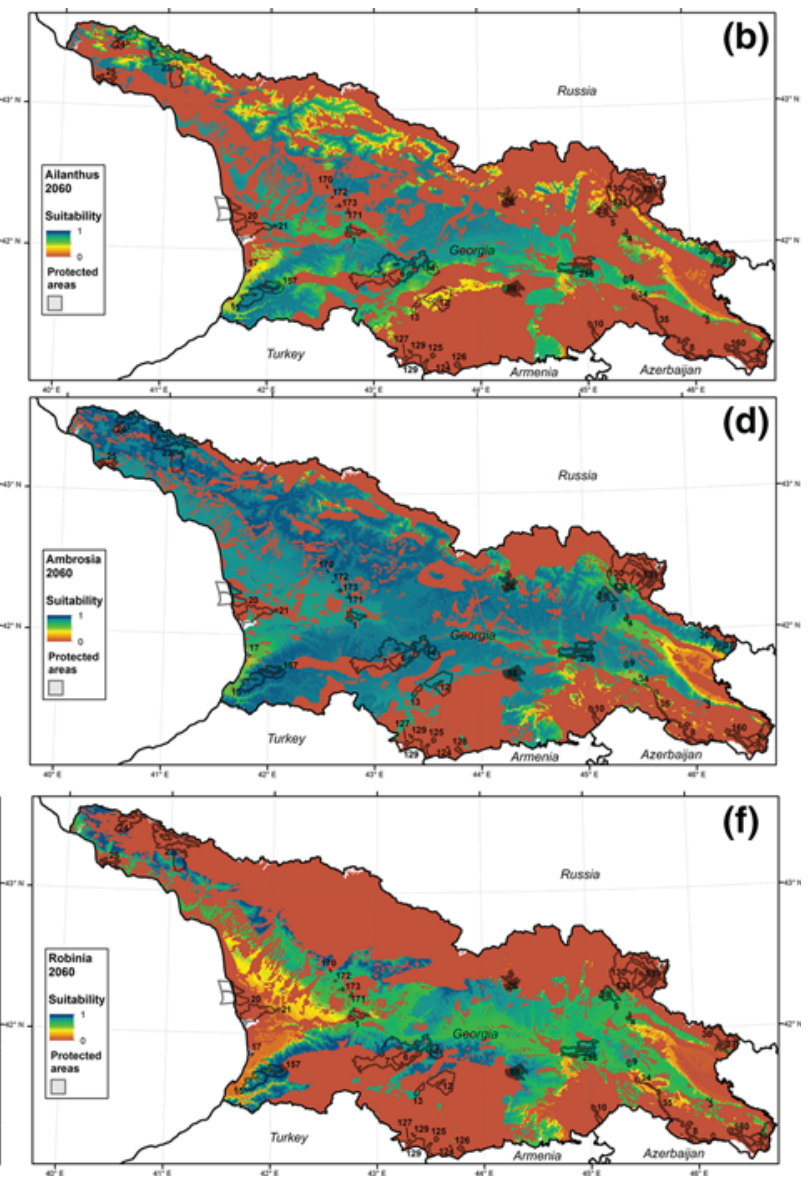

(c, d) and A. altissima (e, f): Different colours show percentage of predicted habitat suitability under current conditions. Asterisks indicate known occurrences of the species and grey frames show Protected Areas (cf. text for details)

Protected Areas in Georgia

The IUCN is the most important organisation for setting and defining the different categories of Protected Areas. The current six categories and one subcategory were defined in 1994 and include: Ia Strict Nature Reserve, Ib Wilderness Area, II National Park, III Natural Monument or Feature, IV Habitat/ Species Management Area, V Protected Landscape/ Seascape, and VI Protected Area with sustainable use of natural resources.

Georgia uses IUCN categories (Anonymous, IUCN 2012) as guidelines to set up their Protected Areas under the law of Georgia on Protected Areas (Anonymous, ELAW 2012). At present the total size of 
Table 1 Threat potential of the studied nine invasive alien plants to Georgia: Biology, habitat, origin (NA: North America, EA: Eastern Asia) and percentage of area predicted to be covered by each of the selected invasive alien plants and for the

Protected Areas alone, and the number of Protected Areas predicted to be occupied by each species under current and future conditions, with respective increase/decrease over the next 50 years

\begin{tabular}{|c|c|c|c|c|c|c|c|c|c|c|c|}
\hline \multirow[t]{2}{*}{ Species name } & \multirow[t]{2}{*}{ Origin } & \multirow[t]{2}{*}{ Life form } & \multicolumn{2}{|c|}{$\begin{array}{l}\% \text { Surface predicted } \\
\text { in Georgia }\end{array}$} & \multirow[t]{2}{*}{$\Delta \%$} & \multicolumn{2}{|c|}{$\begin{array}{l}\% \text { Surface predicted in } \\
\text { Protected Areas }\end{array}$} & \multirow[t]{2}{*}{$\Delta \%$} & \multicolumn{2}{|c|}{$\begin{array}{l}\text { \# Protected } \\
\text { Areas }\end{array}$} & \multirow[t]{2}{*}{$\Delta$} \\
\hline & & & Today & Future & & Today & Future & & Today & Future & \\
\hline A. artemisiifolia & NA & Herb & 23.99 & 25.07 & +1.08 & 40.40 & 43.53 & +3.13 & 36 & 34 & -2 \\
\hline R. pseudoacacia & NA & Tree & 13.82 & 13.28 & -0.55 & 18.93 & 21.36 & +2.42 & 29 & 27 & -2 \\
\hline A. altissima & EA & Tree & 8.73 & 13.19 & +4.46 & 10.54 & 25.10 & +14.55 & 17 & 20 & +3 \\
\hline C. bungei & EA & Shrub & 4.27 & 4.32 & +0.05 & 1.88 & 1.98 & +0.10 & 5 & 5 & 0 \\
\hline O. phaeacantha & NA & Shrub & 0.82 & 1.56 & +0.75 & 0.77 & 1.64 & +0.87 & 2 & 4 & +2 \\
\hline S. japonica & EA & Shrub & 0.62 & 0.29 & -0.32 & 0.29 & 0.00 & -0.29 & 2 & 0 & -2 \\
\hline M. sinensis & EA & Herb & 0.23 & 0.21 & -0.03 & 0.06 & 0.06 & 0 & 1 & 1 & 0 \\
\hline O. humifusa & NA & Shrub & 0.10 & 0.81 & +0.71 & 0.01 & 1.51 & +1.50 & 1 & 4 & +3 \\
\hline$V$. rotundifolia & EA & Shrub & 0.04 & 3.66 & 0 & 0.00 & 0.00 & 0 & 0 & 0 & 0 \\
\hline
\end{tabular}

Protected Areas is 511,123 hectares, which is about $7 \%$ of the country's territory. Forests cover about $75 \%$ of the Protected Areas. They are classified as 14 Strict Nature Reserves, 8 National Parks, 4 Natural Monuments, 15 Managed Nature Reserves and 2 Protected Landscapes (Fig. 1; Table 2). The primary function of these Protected Areas in Georgia is the protection of the natural heritage of the country and of unique natural and cultural monuments (Anonymous, Agency of Protected Areas, Georgia 2009).

Bioclimatic data sets

To calibrate models of the distribution of species, we selected six climatically derived variables considered critical to plant physiological function and survival (Bartlein et al. 1986). These are tmax (maximal temperature of the warmest month), tmin (minimal temperature of the coldest month), tar (temperature annual range), twetq (mean temperature of the wettest month), pwet (precipitation of wettest month) and pdry (precipitation of driest month). Data were obtained from the WorldClim database (Anonymous, WorldClim 2012; Hijmans et al. 2005), and were used in this studywithout modifications and with a resolution of 30 arc seconds $(\sim 1 \mathrm{~km})$ for the calibration of models and the predictions in Georgia, or with a resolution of 10 arc minutes for worldwide predictions ( $\sim 16 \mathrm{~km}$ ) (see next section).

Future climate projections for the decade of 2050 (average for 2041-2060) based on Scenario A1B from the 4th Assessment Report of the IPCC Climate Change 2007 (IPCC Climate Change 2007)were extracted from the WorldClim dataset (Hijmans et al. 2005), for the same six Bioclimatic variables as used for the calibration of the models. The A1 storyline and scenario family describes a future world of very rapid economic growth and global population that peaks in mid-century and declines thereafter, and the rapid introduction of new and more efficient technologies. The three A1 groups are distinguished by their technological emphasis: fossil intensive (A1FI), non-fossil energy sources (A1T), or a balance across all sources (A1B) (IPCC Climate Change 2007).

\section{Species distribution modelling}

We used the occurrence data collected for the selected nine species in combination with the Bioclimatic data to predict the potential distribution of the species in Georgia using a correlative species distribution modelling approach (Guisan and Thuiller 2005). We used the ensemble forecasting approach implemented in the BIOMOD package (Thuiller et al. 2009; version 1.1.14) in $\mathrm{R}$ ( $\mathrm{R}$ Development Core Team Team 2011; version 2.15.0).

This approach that consists in combining predictions of several modelling techniques into one ensemble prediction has been shown to reduce uncertainty in predictions (Araújo et al. 2005). Here we calculate the 


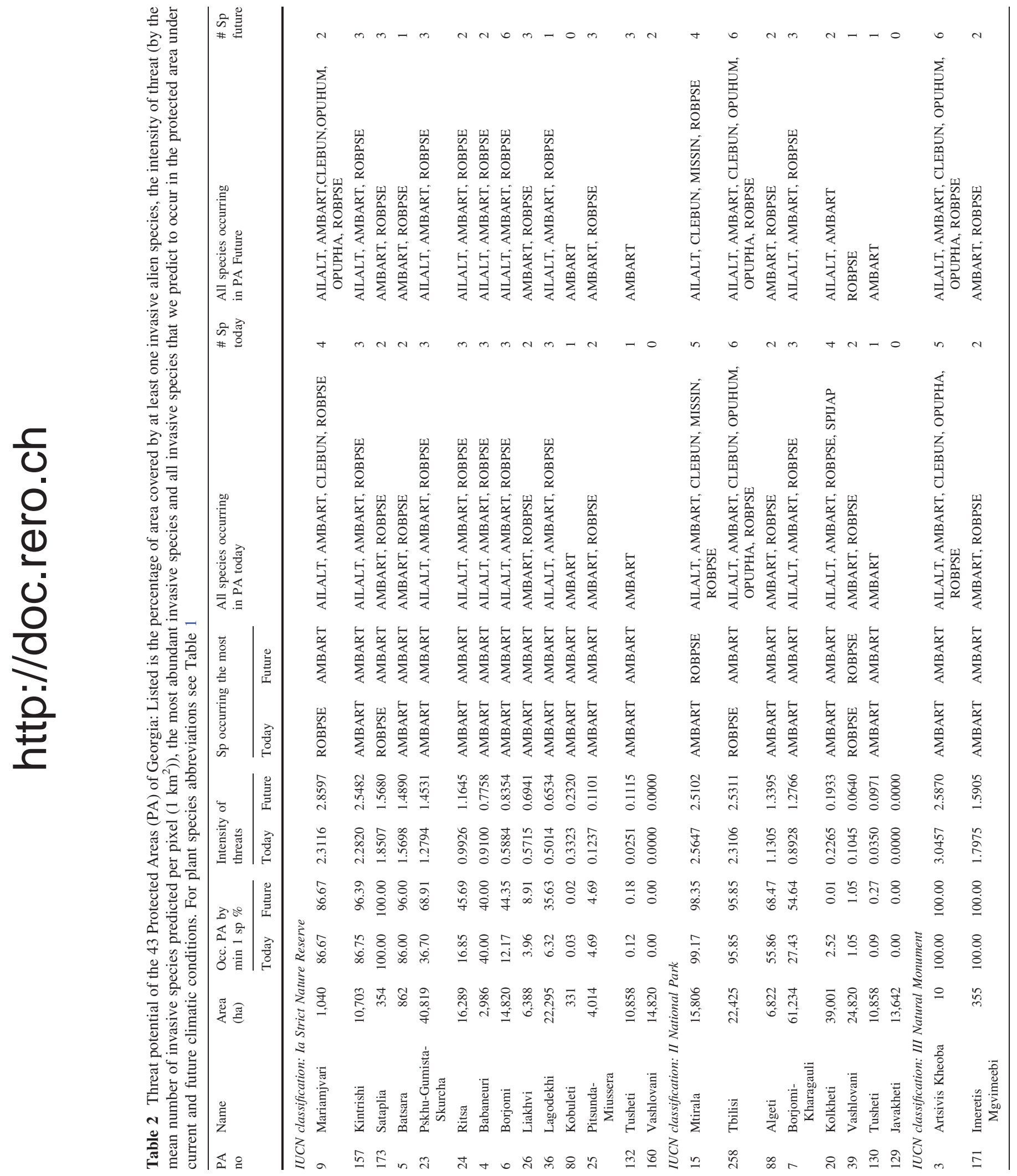




|


median predictions of three different techniques: Gradient Boosting Machine (GBM; Friedman 2001), Random Forest (RF; Breiman 2001) and MaxEnt (Phillips et al. 2006). These modelling techniques are now commonly used for species distribution modelling and further explanations are available in Thuiller et al. (2009). Note that for $C$. bungei, only the models RF and MAXENT were used because there was not enough precise data to run the GBM model.

To calibrate the models, a set of 10,000 absences were randomly drawn within the biomes occupied by the species and used along with the presences to calibrate the models. With this approach we automatically adapt the extent of the study area to each species and make sure that absences are not drawn from regions that have not been accessible to the species since it speciated (Barve et al. 2011). We gave the 10,000 absences the same weight as the presence to ensure a prevalence of 0.5 in the calibration of the models (Phillips and Dudik 2008). We calibrated the models using a random sample of $80 \%$ of the original presence-absence data, and model performance was assessed using the remaining $20 \%$ of the data. Three different methods have been used to evaluate the accuracy of the models: Probability of detection (POD; ranges from 0 to 1; ThuillerW et al. 2009), True Skill Statistics (TSS; ranges from -1 to 1; Allouche et al. 2006)) and Boyce index (ranges from -1 to 1 ; Boyce et al. 2002). POD simply assesses the rate of correctly predicted presences. TSS is similar to a Cohen's kappa index that measures whether the amount of correctly predicted presences is higher than expected by chance, but corrects for the prevalence of occurrences in the dataset (Allouche et al. 2006). The Boyce index measures whether the distribution of predicted values at sites where the species is present correlates with the distribution of predicted values throughout the study area (Hirzel et al. 2006). Here this correlation is measured with Pearson's correlation as in Petitpierre et al. 2012. The entire calibration procedure was repeated 10 times for each species to assess the variability in model performance.

The fitted models were first projected on the whole world with a resolution of $10^{\prime} \times 10^{\prime}$ resolution $(\mathrm{cf}$. Annex 3 for the global model of $A$. artemisiifolia and its statistics as an example) and were then projected on Georgia at a resolution of $\sim 1 \mathrm{~km} \times \sim 1 \mathrm{~km}$. Maps were produced, which show areas where more than $50 \%$ of the models predict the species to be present and thus can be considered as highly suitable for the species. Models calibrated under current conditions were projected into future climates under the scenario A1B (IPCC Climate Change 2007) to generate species distribution maps for the decade 2060.

In order to get more realistic maps of ecological habitat suitability, we used three ecological datasets (kindly provided by Giorgi Mikeladze, Tbilisi Botanical Garden)to filter the resulting potential climatic distributions. These were soil type (69 different types; provided by the Department of Soils, Agricultural University of Georgia; all GIS data were prepared by GIS-Lab), vegetation type (29 types; Bohn et al. 2004) and the differentiation between forest, shrub or open vegetation (created by digitizing soviet topographic maps). The filters were species-specific and exclude soil and vegetation types with no species occurrences in Georgia, based on the recorded occurrences (our field data and herbarium records). Thus, the filtered predicted distributions are subsets of the predicted climate niches including only environment types, where the species can realistically occur.

Finally, all nine maps, one per species, where more than $50 \%$ of the models predicted the species to be present were overlaid under current and future climatic conditions resulting in a combined map illustrating areas suitable for colonization of the nine species and thus, indicating areas with the highest threat potential by the pool of studied IAPs.

\section{Results}

Invasion potential of the nine invasive alien plant species in Georgia and in its Protected Areas

The distribution for each of the nine invasive alien species was predicted based on the occurrences in their native and invaded range. All species distribution models resulted in a good model evaluation score using POD, TSS and Boyce (Annex 4). Based on our habitat suitability analysis for Georgia, we predict the largest potential distribution for A. artemisiifolia, $R$. pseudoacacia and A. altissima for both Georgia as well as the Protected Areas, occurring in 36, 29 and 17 Protected Areas, respectively (out of 43; Table 2; Fig. 1a, c, e). A. artemisiifolia has $23.99 \%$ of the surface area predicted in Georgia and $40.40 \%$ in Protected Areas under current conditions. This will 
slightly increase in the next fifty years to 25.07 and $43.53 \%$, respectively (Fig. 1a, b). Under current conditions, $R$. pseudoacacia is the second most widely distributed, with $13.83 \%$ in Georgia and $18.93 \%$ in Protected Areas (Fig. 2c, d), and occurrences are predicted to remain fairly stable in the next decades. In contrast, under future conditions, A. altissima is predicted to be the second most widely distributed IAP in Protected Areas with $25.10 \%$, due to a very high increase of $14.55 \%$ in the next 50 years (Fig. 1e, f). With $4.27 \%$ surface predicted in Georgia and $1.88 \%$ in Protected Areas, Clerodendrum bungai is a moderately invasive plant and is predicted to be stable over the next 50 years. O. phaeacantha, S. japonica, Miscanthus sinensis, $O$. humifusa and $V$. rotundifolia are predicted to be less invasive than the other species, with areas predicted across Georgia between 0.82 and $0.04 \%$. Finally, V. rotundifolia, a coastal species that has e.g. invaded many fragile beach-dune ecosystems of the southeastern United States (Cousins et al. 2010), occurs in Georgia along the Black Sea coast, but is predicted to not occur in a single Protected Area both under current and future climatic conditions. Furthermore, as a coastal plant, its spread potential will remain limited. C. bungei, S. japonica, $M$. sinensis and $V$. rotundifolia are only predicted in the lowlands of the western part of Georgia in the Adjara region. In contrast, the two Cactaceae species $O$. humifusa and $O$. phaeacantha are only predicted in the drier regions around Tbilisi and the eastern part of Georgia (data not shown). Although predictions indicate doubling of their distribution over the next 50 years, the predicted area remains below $2 \%$ of the Georgia's territory (Table 1).

Predicted combined distribution of all nine invasive alien plants

The combined predicted distribution maps of the IAP, after restriction using the three ecological filters, were projected on the map of Georgia containing the 43 Protected Areas (Fig. 2a). This showed which areas of Georgia, but especially also of the Protected Areas, can be expected to be colonised by a high number of invasive alien species and thus are under the highest risk due to IAP. Two areas, one around Tbilisi and some parts in western Georgia (Adjara),have an especially high threat potential from IAP, with at least 6 species (out to the nine studied ones) having a probability of more than fifty per cent to be present. The region around Tbilisi could be especially endangered in the future, as prediction maps reveal a high increase in pixels where at least six IAP are predicted to be present with a probability greater than fifty per cent due to climate changes. The Adjara region at the Black Sea coast in contrast is expected to stay stable over the next 50 years (Fig. 2b).

Protected Areas most at risk to invasive alien plants

The threat potential for each Protected Area ordered by IUCN classification is given in Table 2. We found 17 Protected Areas that have more than fifty per cent of their area predicted to be suitable for at least one invasive species to occur. Eight of them are quite small with $<1,000$ hectares (cf. Table 2) and their conservation objectives are rather monumental structures (IUCN class III, cf. Table 2) than local biodiversity. Two of the large Strict Nature Reserves have a high percentage of their area predicted to be covered by invasive species under current conditions and are thus exposed to a high risk by IAP. These are the Kintrishi Strict Nature Reserve with $86.75 \%$ of area suitable to be covered and a predicted intensity of threat of 2.28 IAP/ $1 \mathrm{~km}^{2}$ and the Mariamjvari Strict Nature Reserve with $86.67 \%$ of area suitable to be covered and an intensity of threat of 2.31. Furthermore, the area of Kintrishi is predicted to increase in the future by $9.64 \%$. Focusing on the National Parks, also the Tbilisi and the Mtirala National Park are among the most threatened ones with 95.85 and $99.17 \%$, respectively, of area predicted to be occupied by at least one invasive species and a predicted intensity of threat on average of $2.5 \mathrm{IAP} / 1 \mathrm{~km}^{2}$. Among the Managed Nature Reserves we found three specifically threatened parks. These are the Lagodekhi, Nedzvi and the Ilto Managed Nature Reserve, with 96.97, 51.75 and $57.41 \%$ of their area predicted to be occupied by at leastone invasive species under current conditions. The Nedzvi Nature Reserve has the highest increase with $37.06 \%$ over the next 50 years for the area predicted to be occupied.

Our study further indicates that the Protected Areas most threatened by IAP are located at lower altitudes and close to large cities, whereas areas in the Greater and Lesser Caucasus Mountains are less at risk (cf. Table 2). This is well in line with findings by 
Fig. 2 Combined threat potential of the studied nine invasive alien plants in Georgia and its 43 Protected Areas at present climatic conditions (a) and in 2060 (b). Pixels $\left(1 \mathrm{~km}^{2}\right)$ in different colours show how many of these nine species are predicted to be present with a probability higher than $50 \%$
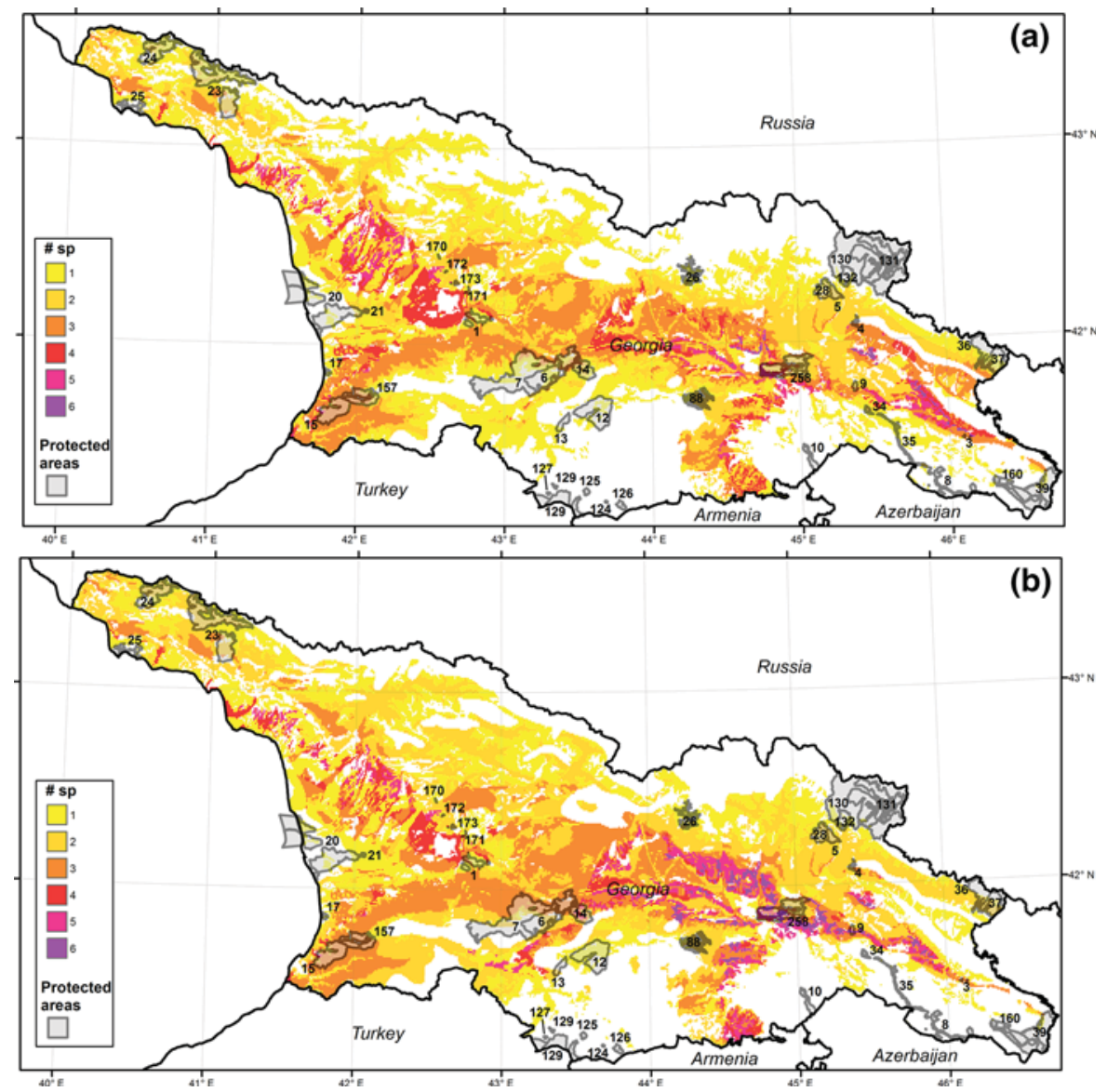

Alexander et al. (2011) and Seipel et al. (2012) who found a significant relationship between altitude and predicted number of invasive species, with more invasive species predicted at lower altitudes.

\section{Discussion}

Species distribution modelling and predicting ecosystem impact of invasive alien plants

Ecological science is challenged to predict potential consequences of global change for biodiversity (Guisan and Rahbek 2011; Nogues-Bravo and Rahbek 2011). To our knowledge, the procedure presented in this study to identify areas of high conservation value most at risk by potentially harmful IAP has been applied for the first time. Bustamante and Seoane (2004) conducted a pilot study in this sense, but this was restricted to just two species of IAP and two target endangered native plants and using generalized linear model. Another similar study was conducted by Vicente et al. (2011), with one IAP threatening one native species. No study so far assessed the potential threat of the most important IAPs at a national level on the native biodiversity under current and future climatic conditions.

Invasion potential of the nine alien plant species in Georgia and in its Protected Areas

Among the studied IAP, the predicted potential distribution was largest for A. artemisiifolia, A. altissima and $R$. pseudoacacia, both across Georgia as well as in the Protected Areas, thus parks are generally affected in the same way as the whole of Georgia (Fig. 1; Table 2). Both A. artemisiifolia and A. altissima are on the black list of invasive plant species of Europe, and M. sinensis is on the Alert List (EPPO 2014), indicating that plants rated as highly 
invasive across Europe also are predicted to be the most invasive ones in Georgia. In turn, our findings with regard to targeted management interventions against IAP thus also have importance for other European countries. A. altissima was predicted to be the one with the highest spread potential over the next 50 years, especially in Protected Areas with a very high increase of $14.5 \%$ to a total of $25.10 \%$ of their area (Fig. 1; Table 1). Two species are predicted to remain stable over time, $M$. sinensis and $V$. rotundifolia, while $S$. japonica may even decreases over the next 50 years (Table 2).

Identifying areas of high conservation value at risk by invasive alien plants

Two regions in Georgia, Tiblisi in the east and Adjara in the west, have been identified to be under special threat by IAP, i.e. ecological conditions of these regions are suitable for many of the invasive species and local biodiversity is therefore under a high risk to be negatively impacted by IAP. There is now substantial evidence that climate change is increasingly affecting species and ecosystems (Brooks et al. 2006; Chen et al. 2011), and thus also the distribution of invasive plant species and their likely impact (Hellmann et al. 2008). Our study showed that Protected Areas at lower altitudes are expected to harbour more IAP than regions at higher altitudes, and that by 2060, the intensity of threat is predicted to be especially high around Tbilisi (Fig. 1; Table 2).

We acknowledge that our approach is just the first step in predicting ecosystem impact of IAP, by identifying those geographic areas where IAP impacts are most likely to occur. Unfortunately, still little is known on ecosystem impacts of IAP (Blackburn et al. 2011; Gurevitch et al. 2011; Vilà et al. 2011; Sun et al. 2013). According to Parker et al. (1999), total impact of an invader includes three fundamental dimensions: (1) range size, (2) abundance or biomass and (3) per-capita or per-biomass effect. In a specific invaded area, invasive species may affect the biogeochemical pools and fluxes of materials and energy, thereby altering the fundamental structure and function of their ecosystems (Ehrenfeld 2010). In $80 \%$ of the cases studied, impact on native plants and/or vegetation composition was indeed found (Pyšek et al. 2012). Nevertheless, impact can be assumed to be larger for more widely distributed than for locally restricted IAP (Parker et al. 1999).

\section{Conclusion}

Ecological science is challenged to predict potential consequences of global change for biodiversity (Pereira et al. 2010, Guisan and Rahbek 2011). Our study showed that predictive species distribution modelling provides a useful and cost effective tool for contributing conservation planning and biodiversity management. It constitutes a novel and innovative approach to identify (1) IAP with high invasion potential both at present time and in the future under climate change and (2) areas of high conservation value that are particularly at risk to become negatively impacted by IAP (i.e. conflict areas). The total size of the 43 Protected Areas in Georgia is 511,123 hectares, which is about $7 \%$ of the country's territory. Our procedure, presently only based on the selected nine study IAS (an extension to 30 IAS is underway), will provide the baseline data needed for authorities and personnel involved in the management of Protected Areas to decide on where to best invest money and time for efficient IPA management by prioritizing IAP with the highest spread potential and Protected Areas most at risk by IAP. Further economic studies that explicitly consider both management costs and damages are needed that include the deductability of specific IAS, the effectiveness of the control method and labor requirements as well as a monetary measure of invasion damages (Cacho et al. 2007; Epanchin-Niell and Hastings 2010). Thus, our findings can significantly contribute to the conservation of Georgia's outstanding biodiversity, by suggesting areas of Georgia where endemic species are most in need of protection actions against the effect of invasive plants. We believe that our predictions are especially realistic, as the models not only consider the climate envelope, but also the ecological niche based on the environmental filters (vegetation and soil types) available at a very high resolution for Georgia. As the Protected Areas are established by the government and managed through the Georgian law, they are a good place where to start conservation actions against IAPs, as the legal tools are already available for them.

As a next step, we are planning to develop and apply IAP monitoring schemes for selected Protected Areas. This will provide accurate and actual spread data of IAP at sites differing in habitat types and climatic conditions, which will in turn help to validate and improve models of IAP spread. In addition and in 
order to give the various IAP some sort of a impact value based on whether a species is known to have impact (on native species, communities or ecosystems), we will use published lists of species that appeared in studies on impact of invasive plants. Combining these values with the present and actual distribution data should further improve our precision in delimiting areas most at risk by IAP and in identifying the IAP of highest concern. Furthermore, studies are presently underway to identify plant biodiversity hotspots based on occurrences of the 380 endemic plants to Georgia that can then be superimposed to areas susceptible to invasion by IAP to more specifically assess the potential impact of IAS to the local and endangered flora.

Acknowledgments We greatly acknowledge Grigol Deisadze and Sandro Kolbai for help with field work, Giorgi Mikeladze for supplying the excellent environmental data for the filters and Dr. Shalva Sikharulidze and Maia Tavartkiladze for hosting us during our research stay at the Tbilisi Botanical Garden. We also thank Info Flora for providing the occurrence data of the nine study species in Switzerland and two anonymous reviewers for the helpful and constructive comments on an earlier version of this manuscript. The study was financially supported by a travel grant for botanical, zoological and earth sciences studies from the Swiss Academy of Science, sc.nat + to DT, and by the NCCR Plant Survival, a research program of the Swiss National Science Foundation, to HMS and OB for travelling to Georgia in 2012.

\section{References}

Alexander JM, Kueffer C, Daehler CC, Edwards PJ, Pauchard A, Seipel T, Consortium M (2011) Assembly of nonnative floras along elevational gradients explained by directional ecological filtering. Proc Natl Acad Sci 108:656-661

Allouche O, Tsoar A, Kadmon RO (2006) Assessing the accuracy of species distribution models: prevalence, kappa and the true skill statistic (TSS). J Appl Ecol 43:1223-1232

Anonymous (2009) Agency of Protected Areas Georgia. Ministry of Environmental Protection and Natural Resources of Georgia. www.apa.gov.ge

Anonymous (2012) Conservation international. www. conservation.org

Anonymous (2012) ELAW, Environmental law alliance worldwide. www.elaw.org/node/1327

Anonymous (2012) IUCN, International union for conservation of nature. www.iucn.org

Anonymous (2012) WorldClim global climate data. www. worldclim.org

Anonymous (2012) WWF, world wildlife found. www.panda. org

Araújo MB, Guisan A (2006) Five (or so) challenges for species distribution modelling. J Biogeogr 33:1677-1688
Araújo MB, Whittaker RJ, Ladle RJ, Erhard M (2005) Reducing uncertainty in projections of extinction risk from climate change. Glob Chang Biol 14:529-538

Bartlein PJ, Prentice IC, Webb T (1986) Climatic response surfaces from pollen data for some eastern North American taxa. J Biogeogr 13:35-57

Barve N, Barve V, Jiménez-Valverde A, Lira-Noriega A, Maher SP, Townsend Peterson A, Soberón J, Villalobos F (2011) The crucial role of the accessible area in ecological niche modeling and species distribution modelling. Ecol Model 11:1810-1819

Beaumont LJ, Gallagher RV, Thuiller W, Downey PO, Leishman MR, Hughes L (2009) Different climatic envelopes among invasive populations may lead to underestimations of current and future biological invasions. Divers Distrib 15:409-420

Blackburn TM, Pyšek P, Bacher S, Carlton JT, Duncan RP, Jarošík V, Wilson JRU, Richardson DM (2011) A proposed unified framework for biological invasions. Trends Ecol Evol 26:333-339

Bohn U, Gollub G, Hettwer C, Neuhäuslová Z, Raus TH, Schlüter H, Weber H (2004) Karte der natürlichen Vegetation Europas/Map of the Natural Vegetation of Europe, $\mathrm{Maßstab} /$ Scale 1:2.500.000, Interaktive/Interactive CDROM- Erläuterungstext, Legende, Karten/Explanatory Text, Legend, Maps. Landwirtschaftsverlag, Münster

Boyce MS, Vernier PR, Nielsen SE, Schmiegelow FKA (2002) Evaluating resource selection functions. Ecol Model 157:281-300

Breiman L (2001) Random forests. Mach Learn 45:5-32

Broennimann O, Guisan A (2008) Predicting current and future biological invasions: both native and invaded range matters. Biol Lett 4:585-589

Broennimann O, Treier UA, Müller-Schärer H, Thuiller W, Peterson AT, Guisan A (2007) Evidence of niche shift during biological invasion. Ecol Lett 10:701-709

Brooks TM, Mittermeier RA, da Fonseca GAB, Gerlach J, Hoffmann M, Lamoreux JF, Mittermeier CG, Pilgrim JD, Rodrigues ASL (2006) Global biodiversity conservation priorities. Science 313:58-61

Bustamante J, Seoane J (2004) Predicting the distribution of four species of raptors (Aves: Accipitridae) in southern Spain: statistical models work better than existing maps. J Biogeogr 31:295-306

Cacho O, Hester S, Spring D (2007) Applying search theory to determine the feasibility of eradicating an invasive population in natural environments. Aust J Agric Resour Econ $51: 425-443$

Chen IC, Hill JK, Ohlemuller R, Roy DB, Thomas CD (2011) Rapid range shifts of species associated with high levels of climate warming. Science 333:1024-1026

Cousins MM, Briggs J, Gresham C, Whetstone J, Whitwell T (2010) Beach Vitex (Vitex rotundifolia): an invasive costal species. Invasive Plant Species Manag 3:340-345

Dirnbock T, Greimler J, Lopez P, Stuessy TF (2003) Predicting future threats to the native vegetation of Robinson Crusoe Island, Juan Fernandez Archipelago, Chile. Conserv Biol 17:1650-1659

Dudley N (ed.) (2008) Guidelines for applying protected area management categories. Gland, Switzerland: IUCN. $\mathrm{x}+86$ pp. ISBN: 978-2-8317-1086-0 
Ehrenfeld JG (2010) Ecosystem consequences of biological invasions. Annu Rev Ecol Evol Syst 41:59-80

Epanchin-Niell RS, Hastings A (2010) Controlling established invaders: integrating economics and spread dynamics to determine optimal management. Ecol Lett 13:528-541

EPPO, European and Mediterranean Plant protection Organisation (2014) www.eppo.int

Friedman JH (2001) Greedy function approximation: a gradient boosting machine. Ann Stat 29:1189-1232

Guisan A, Rahbek C (2011) SESAM - a new framework integrating macroecological and species distribution models for predicting spatio-temporal patterns of species assemblages. J Biogeogr 38:1433-1444

Guisan A, Thuiller W (2005) Predicting species distribution: offering more than simple habitat models. Ecol Lett 8:993-1009

Guisan A, Tingley R, Baumgartner JB, Naujokaitis-Lewis I, Sutcliffe PR, Tulloch AIT, Regan TJ, Brotons L, McDonald-Madden E, Mantyka-Pringle C, Martin TG, Rhodes JR, Maggini R, Setterfield SA, Elith J, Schwartz MW, Wintle BA, Broennimann O, Austin M, Ferrier S, Kearney MR, Possingham HP, Buckley YM (2013) Predicting species distributions for conservation decisions. Ecol Lett 16:1424-1435

Gurevitch J, Fox GA, Wardle GM, Inderjit, Taub D (2011) Emergent insights from the synthesis of conceptual frameworks for biological invasions. Ecol Lett 14:407418

Hellmann JJ, Byers JE, Bierwagen BG, Dukes JS (2008) Five potential consequences of climate change for invasive species. Conserv Biol 22:534-543

Hijmans RJ, Cameron SE, Parra JL, Jones PG, Jarvis A (2005) Very high resolution interpolated climate surfaces for global land areas. Int J Climatol 25:1965-1978

Hirzel AH, Le Lay G, Helfer V, Randin C, Guisan A (2006) Evaluating the ability of habitat suitability models to predict species presences. Ecol Model 199:142-152

IPCC Climate Change (2007) The physical science basis. Contribution of Working Group I to the Fourth Assessment Report of the Intergovernmental Panel on Climate Change. IPCC, Cambridge

Kikodze A, Gokhelashvili R (eds.) (2007) Protected Areas of Georgia. Tbilisi. Report for the Swiss federal Office of the Environment, p. 37

Kikodze D, Memiadze N, Kharazishvili D, Manvelidze Z, Müller-Schärer H (2010) The alien flora of Georgia

Leung B, Roura-Pascual N, Bacher S, Heikkilä J, Brotons L, Burgman MA, Dehnen-Schmutz K, Essl F, Hulme PE, Richardson DM, Sol D, Vilà M (2012) TEASIng apart alien species risk assessments: a framework for best practices. Ecol Lett 15:1475-1493

Mittermeier RA, Gil PR, Hoffman M, Pilgrim J, Brooks T, Mittermeier CG, Lamoreux J, Da Fonseca GAB (2005) Hotspots revisited: earth's biologically richest and most endangered terrestrial ecoregions. Conservation International, Washington, p 392

Mittermeier RA, Turner WR, Larsen FW, Brooks TM, Gascon C (2012) Global biodiversity conservation? The critical role of hotspots. In: Zachos FE, Habel JC (eds) Biodiversity hotspots distribution and protection of conservation priority areas. Springer, Berlin, Heidelberg, pp 3-22
Müller-Schärer H, Collins AR (2012) Integrated weed management. In: Jorgensen SE (ed) Encyclopedia of environmental management. Taylor and Francis, New York

Nogues-Bravo D, Rahbek C (2011) Communities under climate change. Science 334:1070-1071

Parker IM, Simberloff D, Lonsdale WM, Goodell K, Wonham M, Kareiva PM, Williamson MH, Von Holle B, Moyle PB, Byers JE, Goldwasser L (1999) Impact: toward a framework for understanding the ecological effects of invaders. Biol Invasions 1:3-19

Pauchard A, Kueffer C, Dietz H, Daehler CC, Alexander J, Edwards PJ, Arévalo JR, Billeter R, Cavieres L, Guisan A, Haider S, Jakobs G, Mack RN, McDougall K, Millar C, Naylor BJ, Parks C, Poll M, Rew LJ, Seipel T (2009) Ain't no mountain high enough: plant invasions reaching high elevations. Front Ecol Environ 7:479-486

Pereira HM, Leadley PW, Proença V, Alkemade R, Scharlemann JPW, Fernandez-Manjarrés JF, Araújo MB, Balvanera P, Biggs R, Cheung WWL, Chini L, Cooper HD, Gilman EL, Guénette S, Hurtt GC, Huntington HP, Mace GM, Oberdorff T, Revenga C, Rodrigues P, Scholes RJ, Sumaila UR, Walpole M (2010) Scenarios for global biodiversity in the 21 st century. Science 330:1496-1501

Petitpierre B, Kueffer C, Broennimann O, Randin C, Daehler C, Guisan A (2012) Climatic niche shifts are rare among terrestrial plant invaders. Science 335:1344-1348

Phillips SJ, Dudik M (2008) Modeling of species distributions with Maxent: new extensions and a comprehensive evaluation. Ecography 31:161-175

Phillips SJ, Andersonb RP, Schapire RP (2006) Maximum entropy modelling of species geographic distributions. Ecol Model 190:231-259

Pyšek P, Jarošík V, Hulme PE, Pergl J, Hejda M, Schaffner, Vilà M (2012) A global assessment of invasive plant impacts on resident species, communities and ecosystems: the interaction of impact measures, invading species' traits and environment. Glob Chang Biol 18:1725-1737

R Development Core Team (2011) R: a language and environment for statistical computing, 3-900051-07-0R

Richardson DM, Pyšek P, Rejmánek M, Barbour MG, Panetta FD, West CJ (2000) Naturalization and invasion of alien plants: concepts and definitions. Divers Distrib 6(2):93-107

Richter R, Berger UE, Dullinger S, Essl F, Leitner M, Smith M, Vogl G (2013) Spread of invasive ragweed: climate change, management and how to reduce allergy costs. J Appl Ecol 50(6):1422-1430

Rodriguez JP, Brotons L, Bustamante J, Seoane J (2007) The application of predictive modelling of species distribution to biodiversity conservation. Divers Distrib 13:243-251

Seipel T, Kueffer C, Rew L, Daehler C, Pauchard A, Naylor B, Alexander JM, Edwards PJ, Parks CG, Arevalo J, Cavieres L, Dietz H, Jakobs G, McDougall K, Otto R, Walsh N (2012) Processes at multiple spatial scales determine nonnative plant species richness and similarity in mountain regions around the world. Glob Ecol Biogeogr 21:236-246

Sun Y, Collins AR, Schaffner U, Müller-Schärer H (2013) Dissecting impact of plant invaders: do invaders behave differently in the new range? Ecology 94:2124-2130

Thuiller W, Richardson DM, Pysek P, Midgley GF, Hughes GO, Rouget M (2005) Niche-based modelling as a tool for 
predicting the risk of alien plant invasions at a global scale. Glob Chang Biol 11:2234-2250

ThuillerW Lafourcade B, Engler R, Araújo B (2009) BIOMOD - a platform for ensemble forecasting of species distributions. Ecography 32:369-373

Vicente J, Randin CF, Goncalves J, Metzger MJ, Lomba A, Honrado J, Guisan A (2011) Where will conflicts between alien and rare species occur after climate and land-use change? A test with a novel combined modelling approach. Biol Invasions 13:1209-1227

Vilà M, Espinar JL, Hejda M, Hulme PE, Jarošík V, Maron JL, Pergl J, Schaffner U, Sun Y, Pyšek P (2011) Ecological impacts of invasive alien plants: a meta-analysis of their effects on species, communities and ecosystems. Ecol Lett 14:702-708 